This article discuss art at higher education context considering the idea of multiculturalism as "to learn and to see through borders" (Hughes, 1993, p.84). The established border as the tension point for this study comprehends the concepts on 'erudite', 'popular' and 'folk', taking them as susceptible to 'expansion', 'encounters' and 'articulation' steaming from experiences in the teaching in a critically way. The dichotomies that have been separating art universes will be treated, as cause of tensions that processes hybrid spaces, beneficial to alternative propositions within a critical pedagogical approach. Key-words: art education, higher education, cultural diversity. 


\section{Variações em torno dos jogos estéticos, artísticos e pedagógicos no ensino "superior" de artes visuais}

Este texto é um exercício de como pensar a universidade como família pode ajudar a gerar ações alternativas e questionamentos que construam posturas críticas de pluralidade e diversidade cultural. Meu foco é o ensino "superior" de artes visuais. Procuro refletir sobre jogos estéticos e pedagógicos que estruturam de maneira visível ou velada este ensino. Questiono a formação centrada em padrões eurocêntricos. O que esperar desses futuros profissionais (artistas, professores, designers, dentre outras possibilidades), se eles lidam nos seus cursos de formação com rígidos padrões de arte e cultura?

Palavras-chave: ensino de arte, universidade, diversida- 
De uma certa vez, estava num carro, no interior do Piauí, com outros professores pesquisadores da UFPi e da UnB. Éramos uma equipe e estávamos a serviço do Centro Regional de Desenvolvimento Infantil, que pertencia à Pastoral da Criança. Carro de boléia é um objeto muito apreciado naquelas paragens. O ouvido do povo é apurado, educado, escuta de longe o ronco do motor e logo a pessoa vem pra beira da estrada com alguma coisa a ser transportada: sacos de farinha, bola de arame, cabrito, eles próprios, etc. O que importa é a possibilidade de ir-e-vir. A carroceria foi ficando apertada... E a conversa mais aberta... De repente, um senhor olha para gente e pergunta: "De que 'famia' vocês são"? Alguém do "meu grupo" responde: "Nós somos da Universidade..." Ao que o senhor prontamente constata: "Conheço essa 'famia', não senhor!".

Meu trabalho tem como palco o ensinar arte nessa "famia" que aquele senhor disse não conhecer: a universidade. É ela o cenário da minha escritura pedagógica, no qual busco a pluralidade de vozes, inclusive a daquele senhor. Uma escritura de riscos múltiplos e de buscas incertas, nas quais transitam e dialogam as mais diferentes vozes. Mas nem sempre essas vozes são percebidas. Procuro apurar o ouvido para elas, incluindo a minha própria voz, e em vez de ter um eixo norteador, adotar a idéia de um feixe. Pergunte-se àquele senhor: "O que é um feixe?" "De lenha”, ele responderá. Como que eu sei? Por que também pertenço àquela família, a uma família sertaneja, na qual feixe faz parte do vocabulário corrente.

Lenha para fogueira, para alumiar o cenário que estou procurando montar, narrando minha escritura pedagógica no ensino de arte na universidade. Universidade atravessada por crises, nas quais atores, conteúdos, campos disciplinares, roteiros são sistematizados, questionados, reelaborados, gerando impasses pedagógicos e estéticos. Nas brechas desses impasses, reside a minha deixa.

A universidade é um dos lugares da formação de profissionais de arte e de seu ensino, e espera-se que esses profissionais estejam bem preparados para interagir em contextos culturalmente plurais e híbridos; para reconhecer as instâncias ideológicas de dominação que determinadas formas culturais exercem umas sobre as outras; e para identificar como "construções" 
estéticas e pedagógicas, todas elas valorativas, são transmitidas como totalidades. Os jogos estéticos e pedagógicos são centrais no ensino de artes.

Embora minhas reflexões possam ser expandidas para outras instâncias do processo de ensino, meu alvo é o ensino de artes visuais dentro da própria universidade. Acredito que pensar a família universidade pode ajudar a gerar ações alternativas e questionamentos que construam posturas críticas de pluralidade e diversidade cultural. Os cursos "superiores" de arte formam profissionais que irão atuar em diferentes contextos institucionais educativos (formais e não-formais) e enfrentam realidades cada vez mais dinâmicas. O que esperar desses futuros profissionais (artistas, professores, designers, dentre outras possibilidades), se eles lidam nos seus cursos de formação com rígidos padrões de arte e cultura? Dentre muitas controvérsias que as instituições universitárias têm enfrentado, destaca-se um intenso questionamento sobre suas responsabilidades sociais, ao lado da formação acadêmica.

Podemos considerar a universidade como uma rede de conversações. No entanto, a universidade tem dificuldade de "conversar" consigo e sobre si própria. E ao falar de si própria, a universidade fala de seus conflitos como instituição histórica, fala dos saberes ali sistematizados e da finalidade desses saberes. Para Boaventura de Sousa Santos (1999), a universidade atual enfrenta três crises que são inter-relacionadas: a crise de hegemonia, a crise de legitimidade e a crise institucional. Interessa-me entender essas três crises porque meu trabalho busca nelas espaços para atuar criticamente.

Na crise de hegemonia, a questão mais latente é a contradição entre a alta cultura e a produção de padrões culturais médios e de conhecimentos úteis para formação de força de trabalho qualificada exigida pelo desenvolvimento industrial. Segundo Santos (1999), a crise de hegemonia surge logo nos primórdios, quando a sociedade liberal começa a exigir formas de conhecimento (técnicos) que a universidade tem dificuldade de incorporar. Os cursos de Design, por exemplo, representam um campo de batalha entre o conhecimento estético e histórico da arte e sua aplicabilidade técnica. Geram 
tensões internas, na aprendizagem dos alunos, e externas, na formação que estes levam para o mercado. Outro exemplo pode ser identificado na produção de uma literatura "facilitadora", como as coleções "O Que é" e "Primeiros Passos", não reconhecida pelo status acadêmico, mas amplamente utilizada pelo público universitário.

A crise de legitimidade revela a contradição entre a hierarquização dos saberes especializados, estabelecida mediante a restrição de acesso e da credencialização das competências, e as exigências sociopolíticas da democratização e da igualdade de oportunidades. Ou seja, existe uma falência dos objetivos socialmente assumidos pela universidade, por exemplo; ser democrática e interagir com a sociedade. As formas de acesso vestibulares e/ou provas específicas - representam mecanismos de controle desse papel democrático, uma vez que a realidade das instituições não acompanha a ideologia da "educação para todos". Os mecanismos desenvolvidos para interagir com a sociedade começam com uma contradição interna da questão. "Interagir com" demonstra uma situação de externalidade, ou seja; a universidade é uma coisa e a sociedade é outra, quando, na verdade, a universidade é a própria sociedade. À medida que a crise de legitimidade se intensifica, mecanismos compensatórios são criados para ajudar a restaurar o elo perdido com a sociedade, ou seja, consigo própria.

A crise institucional expõe a contradição entre a reivindicação da autonomia para a definição de valores e os objetivos institucionais. Entre a submissão crescente a critérios de eficácia e a produtividade de origem e natureza empresarial. Para nosso contexto, no qual o modelo iluminista de universidade prevalece, o princípio da autonomia é o marco supremo da libertação da universidade, da igreja e do Estado.

A ameaça a essa autonomia, entretanto, vem de setores externos, como o mercado. Vem também internamente, devido ao estabelecimento do campo institucional do qual a universidade faz parte e é por ele regulada e gerenciada. Assim, tanto o MEC - Ministério da Educação e Cultura - quanto os órgãos de fomento à pesquisa como CAPES (Coordenação de Apoio à Pesquisa na Educação Superior) e CNPq (Conselho Nacional de 
Desenvolvimento Científico e Tecnológico) representam instâncias reguladoras, que nem sempre estão de acordo com os rumos da academia. Por um lado, é cobrada a produção docente intelectual, por outro; exige-se que a universidade se abra para o mercado, como as “incubadoras de negócios” em cursos como o de Design.

Nos cursos de Artes Visuais, esse incômodo fica mais acirrado em face da prevalência da "arte pela arte", sustentada pelo modernismo e renovada no discurso da arte contemporânea. Design, novamente, surge como "solução", pois, como curso de caráter pragmático, abre espaço para formas de prestações de serviço - os escritórios-modelo - deixando "a arte" livre dessas vicissitudes.

Essas crises no sistema universitário eclodiram nos últimos 20 anos e continuam em processo até hoje. Concordo com Santos quando aponta a crise da hegemonia como a mais ampla das três, porque nela está em causa a exclusividade dos conhecimentos que a universidade produz e transmite. Nas universidades brasileiras, essa crise evidencia-se a partir da década de 60, com a expansão do "ensino superior" e do acesso a ele por camadas mais amplas da população.

Mais uma vez, recorro ao Design para exemplificar e colocar essa questão. Existe uma expressão comum entre os jovens alunos que chegam ao curso de Design na UFG para se diferenciarem dos que são "Designers autodidatas"; estes são chamados de "micreiros". Mas quais seriam os fatores que distinguiriam um do outro? Ou melhor, que tipo de aprendizagens não-formais habilitam uma pessoa a exercer a profissão sem recorrer a um curso superior? Como um micreiro se transforma em um designer gráfico ou em um comunicador visual?

(...) O conhecimento não pode ser considerado uma ferramenta ready made, que pode ser utilizada sem que sua natureza seja examinada. Da mesma forma, o conhecimento do conhecimento deve aparecer como necessidade primeira, que serviria de preparação para enfrentar os riscos permanentes de erro e ilusão, que não cessam de parasitar a mente humana (MORIN, 2000, p. 14). 


\section{Mapeamento e perspectivas}

A partir da década de 60 , com a democratização do cenário universitário e a presença nele da classe média, os atores começam a se diversificar. É significativa a inserção de mulheres no ensino superior a partir dessa década. Essa inserção gera tanto conflitos em campos tradicionalmente masculinos, como as engenharias, como também a reificação de campos tradicionalmente femininos, como é o caso da pedagogia. Quanto à diversidade étnica, é fato que o público universitário tornou-se mais mestiço. No entanto, apesar da expansão democrática, não existe um contingente negro significativo nas universidades. Não podemos afirmar que a maioria do público é branca, pois raça, no Brasil, é um dado de fato complicado. Ainda assim, não podemos dizer que houve um aumento significativo de índios e negros nos quadros de ensino superior. A polêmica diante das políticas afirmativas das cotas para negros mostra a complexa relação entre classe econômica social e raça neste país. Neste país, raça e classe são quase sinônimos.

O estado brasileiro de maior população negra do país é a Bahia (81,1\%). Em sua capital, Salvador, os negros têm uma taxa de desemprego $45 \%$ superior à população não-negra. $\mathrm{Na}$ região metropolitana de São Paulo, enquanto 30.5\% dos ocupados não-negros trabalham em cargos de direção e planejamento, apenas $13.5 \%$ dos ocupados negros estão nesses postos de comando. Dados nada estimulantes para um país com a segunda maior população negra do mundo, que chega pouco e aos poucos ao ensino superior. Segundo pesquisa divulgada pelo IBGE, na Síntese de Indicadores Sociais, seis em cada dez estudantes de universidades públicas no Brasil pertencem às camadas mais ricas da população. Disponível: http://www.folhaonline.com.br (13/06/2003).

Em relação ao repertório cultural que os jovens trazem para a universidade, esse é basicamente construído a partir de influências vindas da televisão, principalmente da MTV, do cinema norte-americano, das redes telemáticas, dos gibis, dos videoclipes, da música comercial, enfim, de toda uma cultura industrializada, com a qual os jovens convivem diuturnamente. É interessante verificar com os alunos que esse repertório "massificado" é 
um desperta-desejos pela formação universitária em artes. É patente a falta de familiarização de boa parte deles (se não a maioria) com galerias de arte, museus, ou outros espaços da chamada arte erudita ou de código alto.

Muitos alunos que chegam aos cursos superiores desenham ou têm ligação com fanzines, gibis, mangás, internet e jogos eletrônicos, mananciais de imagens artísticas. É comum a decepção do aluno com relação ao tipo de disciplina que esperava ter nos cursos de arte, nos quais existe pouco espaço para o aprendizado prático e uma supervalorização da teoria. Por outro lado, muitos jovens familiarizados com softwares com recursos visuais cada vez mais sofisticados, tais como photoshop e corel draw, escolhem o Design e, ilusoriamente, projetam nessa profissão uma possibilidade de ascensão profissional no campo da arte.

Como lidar com essas crises? Fingir que não existem é, no mínimo, menosprezar a inteligência dos nossos educandos. Aceitá-las passivamente é ficar no estágio inicial dos nossos impasses. As dicotomias trazidas por essas crises estimulam minha prática pedagógica. Dicotomias entre alta cultura x cultura popular, entre educação x trabalho e teoria x prática estão presentes em todas as instâncias dos cursos de Artes Visuais nas universidades. A cultura de massas tem uma lógica distinta da cultura universitária, mas se confunde com ela. Como diz Santos (1999), a cultura de massas é muito mais dinâmica, e seus produtos vão apertando o cerco à alta cultura, quer porque reciclem constantemente os produtos desta, quer porque concorrem com ela na formação do universo cultural dos estudantes. Num país que historicamente tem negado à sua população o acesso à educação, protelado e dificultado a educação superior, a expansão desse setor, idealizada nos discursos, na prática constitui-se num problema. Quantidade traz diversidade!

Muitas expressões culturais estão presentes nas universidades, nas escolas e, em particular, na sala de aula. Não as percebemos por não serem 'tão óbvias' quanto branco versus negro. Algumas diferenças, tais como homem x mulher e homo $\mathrm{x}$ hetero podem ser biológicas ou de orientação sexual, mas as representações em torno delas são construções socioculturais 
e econômicas que revelam jogos de poder, inclusão e exclusão. Não basta tentar conciliar oposições; deve-se também saber o que estas revelam e que estratégias pedagógicas podemos desenvolver nas brechas que formam, para trabalhar os conflitos de forma crítica.

Considere cultura como o conjunto de significados, expectativas e comportamentos compartilhados por um determinado grupo social, o qual facilita e ordena, limita e potencia os intercâmbios sociais, as produções simbólicas e materiais e as realizações individuais e coletivas dentro de um marco espacial e temporal (GÓMEZ, 2001, p. 17).

O conflito é um espaço para atuarmos como educadores críticos, aprendendo com o mestre Freire que uma das tarefas do educador crítico é traduzir diferenças culturais. Rever saberes já sistematizados, mas também deflagrar novas posturas que se estendam além da sala de aula. Fazer perguntas é uma constante. Elas surgem na minha prática de diferentes maneiras e em diferentes ocasiões. Alinhavam êxitos e fracassos, desânimos, projetos, etc. Por exemplo: como o professor se percebe culturalmente? Como percebe os alunos culturalmente? Como percebe a escola e a sala de aula culturalmente? No que diz respeito aos alunos: como se percebem? Como se apresentam? Que tipo de linguagem usam entre si e com os professores? Também os conteúdos devem ser questionados: quais são e como são selecionados? Da maneira como são organizados, favorecem os diálogos? Os alunos se reconhecem neles? O professor se reconhece neles? Nós, os professores universitários, nos reconhecemos como família? Enfim, a sociedade conhece a "família universidade" e se reconhece nela? Essas perguntas buscam respostas plurais, provisórias e atentas aos processos de subjetivação.

Na guerra - ou no diálogo - das linguagens e dos saberes, o limiar é o (não) lugar que propicia as idas e vindas, o trânsito através dos textos, das culturas, das territorialidades lingüísticas e geográficas. Desloca-se aqui a lógica da qual o pensamento clássico operou as dicotomias, as exclusões, as hierarquias (HOISEL, In COUTINHO, 2001, p. 75). 
Hoisel (2001) comenta que a mudança da metáfora da árvore (desenho da raiz) que dominou (e ainda domina) o pensamento ocidental para a metáfora do rizoma de Deleuze e Guattari (desenho de tubérculos) fornece uma imagem mais aproximada do pensamento contemporâneo que procede por fragmentação. É numa formação rizomática que vejo os novos saberes /teorias / práticas pedagógicas que, inter-relacionados, apóiam o exercício do ensinar/ aprender arte. As transformações dos campos da história e da antropologia, e a constituição de campos híbridos, tais como os estudos culturais, os estudos feministas, os estudos pós-colonialistas, dentre muitos outros que abraçam o múltiplo, a "diferença" e o "outro", trazem para o campo pedagógico abordagens multiculturais e, mais recentemente, a discussão sobre cultura visual e ensino de arte.

A construção paulatina da minha escritura e do palco/cenário representa também o esforço dessa passagem, nem sempre tranqüila, como público, atriz e roteirista da vida na academia, quando busco a superação das dicotomias dos conhecimentos arrumados no modelo hierárquico de árvore.

A centralidade da universidade enquanto lugar privilegiado da produção de alta cultura e conhecimento científico é um fenômeno do século XIX, do período do capitalismo liberal [...] A dicotomia alta cultura - popular constitui o núcleo central do ideário modernista. [...] Incapaz de transformar esta nova cultura (a de massas) numa cultura-objeto, a universidade deixa de ser o produtor central da cultura-sujeito e nessa medida perde a centralidade (SANTOS, 1999, p. 193).

Os paradoxos que estão no cerne das crises de hegemonia, de episteme e dos paradigmas revelam-se operantes na produção de determinados discursos teóricos acima citados e estão presentes no ensino superior de arte, revelando hierarquias. Presenças e ausências indicam jogos de valores estéticos e pedagógicos no ensino de arte. Mais do que reconhecê-los é importante desvelar a relação de poder que os sustentam. 


\section{Periferias estéticas e pedagógicas}

As disciplinas que enfatizam a relação arte-cultura são relegadas ao espaço periférico. Geralmente, não têm espaço para dialogar com os núcleos intermediários ou central do currículo. A arte de grupos étnicos foi oportunamente folclorizada, e é dessa forma que entra no currículo, vinculada mais exatamente às licenciaturas, para suprir uma necessidade de um ensino supostamente menos "artístico" e mais "pedagógico".

A representação dos índios obedecia quase a um programa, e era importantíssimo à consolidação e mantença do predomínio europeu na América. O índio representado na iconografia européia é o índio bárbaro, selvagem, antropófago - incapaz, por todos esses atributos, de gerir a própria vida, e justificando, sem maiores problemas, a dominação européia - tanto a econômica e política quanto a espiritual, viabilizada pela catequese (MELLO E SOUSA, In RAMINELLI, 1996, p. 9).

Na sala dos esquecidos, a mulher também ocupa "um lugar de honra", apesar de representar uma parcela significativa da população universitária, em especial nos cursos de Artes Visuais, e apesar do papel histórico de artistas mulheres na renovação do nosso cenário artístico-cultural. A produção artística das mulheres continua encontrando dificuldades na cena estético-pedagógica. O movimento feminino, que recuperou politicamente os espaços domésticos e pessoais, invertendo o jogo de valorações estéticas, parece não ter afetado os cursos de artes visuais do país.

Barbosa (1995) afirma que, no Brasil, o desafio do modernismo contra as definições tradicionais de Belas Artes deu visibilidade à arte das mulheres. Ressalta, ainda, que essa visibilidade não foi suficiente para garantir o reconhecimento às duas grandes artistas do modernismo, que no final da vida pintavam o que a sociedade esperava, e, talvez, ainda espera das mulheres: natureza morta e pinturas religiosas. Uma dessas artistas, a paulista Tarsila do Amaral, branca, de família rica e proprietária de escravos, pintou, em 1923, o quadro "A Negra", considerado por Barbosa como uma grande homenagem à negritude do Brasil. Antes de Tarsila, as mulheres negras eram representadas, mes- 
Variações em torno dos jogos estéticos, artísticos e pedagógicos no ensino "superior" de artes visuais

mo pelas artistas mulheres, de maneira estereotipada, aos moldes dos colonizadores (BARBOSA,1995, p. 24).

A arte de negros, índios, mulheres, mestiços, gays e pobres parece não ter lugar na família universidade. Apesar das transformações da arte contemporânea com seu campo expandido ${ }^{2}$, o seu ensino em si tem dificuldade em se expandir, ou melhor, em falar e ouvir múltiplas vozes. Polifonia, só como conceito. Artística, estética e pedagogicamente, os esquecidos são muitos.

A unidade, a mestiçagem e a diversidade devem se desenvolver contra a homogeneização e o fechamento. A mestiçagem não é apenas a criação de novas diversidades a partir do encontro; torna-se, no processo planetário, produto e produtor de religação e de unidade. Introduz a complexidade no âmago da identidade mestiça (cultural e racial) (MORIN, 2000, p. 78).

\section{Narrativas}

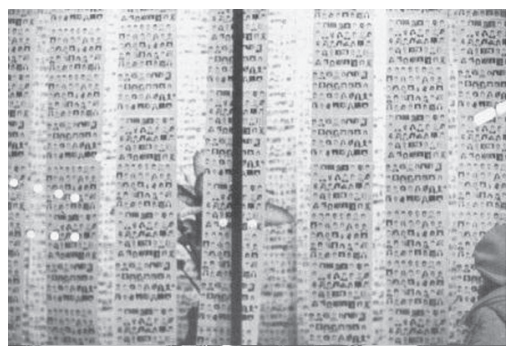

Regina Vater - Instalação - Comigo Ninguém Pode (detalhe), 1984 estrutura de madeira, tecidos, retratos $3 \times 4$ impressos por serigrafia e planta comigo-ninguém-pode. Registro fotográfico da artista

Neste trabalho, a artista utiliza retratos $3 \times 4$ comprados num lambe-lambe do centro do rio de Janeiro. Ela teve que explicar ao fotógrafo que suas intenções eram boas, que não iria fazer bruxaria com as fotos. Na instalação, as tiras impressas com a multiplicidade de imagens do povo brasileiro cercam num espaço triangular um altar com terra no qual está a planta comigo ninguém pode no centro remetendo justamente ao sentido de proteção e de empoderamento do povo brasileiro representado no anonimato dos retratos, a sua diversidade e 
multiplicidade, bem como sua capacidade regenerativa. Os esquecidos pedagogicamente são neste trabalho de Regina, ritualisticamente recuperados no espaço da arte.

As dicotomias que têm separado os universos artísticos, estéticos e pedagógicos podem ser tratadas como tensões que abrem espaços híbridos, oportunos e propícios para propostas alternativas de ensino e aprendizagem de arte. A obra de Regina Vater "comigo ninguém pode" é uma narrativa do povo brasileiro. A planta de fato encontra-se numa boa parte dos lares no Brasil. Assumi, neste trabalho, a forma da narrativa. Narrativas e escritura, a princípio representam duas tradições: oral e escrita. A narrativa é um recorte da minha prática num determinado contexto de tempo e espaço, no qual dúvidas e inquietações foram sendo geradas, e gerando, por sua vez, buscas e experimentações pedagógicas. Entendo escritura como uma escrita, marca pessoal. Aproprio-me do conceito do vocabulário corrente da arte contemporânea e, assim como a artista, acredito que a professora também tem sua escritura. Acredito também que a minha escritura tem a ver com a recusa de um pensamento baseado em dicotomias e oposições, com a recusa do silenciar (inclusive do corpo) e com a necessidade de considerar a multiplicidade de vozes no processo pedagógico. Escritura reúne teoria e prática, 'ação pensada, 'pensamento agido'.

A tradição oral e a tradição escrita aparentemente excludentes confundem-se no dia-a-dia e dialogam em escrituras artísticas, por exemplo, no trabalho de Bispo do Rosário, Mira Schendel, Leonilson, Cabelo, dentre outros. Imbricam-se nas elaborações de significados e interações de sentido que vão sendo re-construídos nas histórias de vida de cada pessoa. Imbrincam-se também na minha vida de professora.

Conto muitas histórias, dentro e fora da sala de aula, e creio que sejam componentes importantes na minha "didática". As que foram colocadas neste texto foram contadas tantas vezes, inclusive fazem parte da minha tese de doutorado. Conto para ouvir a minha voz, para estabelecer um jogo com minhas reflexões teóricas. Conto como quem joga búzios, tento ler nas entrelinhas, interpretar os sinais. A cada jogada, novas revelações, que pedem diferentes interpretações. A narrativa é, atualmente, um 
recurso para nós, professores. Para fazermos nossas vozes serem ouvidas e nos posicionarmos como sujeitos da prática estética, artística, pedagógica que orienta nosso viver, não sem conflitos, na família universidade.

\section{Notas}

1- Segundo Morais, a Arte Postal surge com um cartão-postal que era a montagem com pedaços e quatro outros cartões que Duchamp envia a seus vizinhos. (...) A Arte Postal serviu para aumentar a circulação da obra de arte em todo o mundo, permitindo que artistas que viviam em suas pequenas cidades, inclusive nos países socialistas, participassem de mostras nacionais e internacionais, além de reunir criadores de várias áreas, acabando com a compartimentalização artística (MORAIS, 2001, p. 30).

2- Campo expandido - Campo ampliado - termo cunhado pela crítica de arte norte-americana Rosalind Krauss. O campo ampliado é gerado pela problematização do conjunto de oposições entre as quais está suspensa a categoria modernista escultura (...) Escultura não é mais apenas um único termo na periferia de um campo que inclui outras possibilidades estruturadas de formas diferentes (KRAUSS, 1997). 


\section{Referências Bibliográficas}

ARAUJO, J. Z. A Negação do Brasil: o negro na telenovela brasileira. São Paulo: Editora SENAC São Paulo, 2000.

BARBOSA, A. M. (org.). Inquietações e mudanças no Ensino da Arte. São Paulo: Cortez, 2002.

BARBOSA, A. M. (org.). Arte-Educação: Leitura no Subsolo. São Paulo: Cortez, 1997.

A Importância da Imagem no Ensino da Arte: Diferentes Metodologias. In: Parâmetros Curriculares Nacionais - Arte e a Rede Arte na Escola. Porto Alegre, 1998.

Arte-Educação: 10 anos Depois. AR'te, São Paulo, $n^{\circ} 1$, p.

3-5, 1982.

BASTOS, F.M.C. Making the familiar strange: theacher's interpretations of community art: a case study. Tese de Doutorado Indiana University, USA. 1998.

BHABHA, H.K. O Local da Cultura. Belo Horizonte: Editora UFMG, 2001.

CANCLINI, N. G. Culturas Híbridas. São Paulo: EDUSP, 1998.

CERTEAU, M. A invenção do cotidiano: 1. artes de fazer. Petrópolis: Vozes, 1994.

COUTINHO, E. (org.) Fronteiras imaginadas: cultura nacional/teoria internacional. Rio de Janeiro: Aeroplano, 2001.

DANIEL, Vesta \& COLLINS, C. Community visions. Pp. 81-94. In Ed. Carlos Basualdo, Face Your World. Columbus, OH: Wexner Center for the Arts/The Ohio State University, 2002.

GIROUX, Henry. Atos Impuros: A prática política dos estudos culturais. Porto Alegre: Artmed, 2003.

GOMEZ, A. I. P. A cultura escolar na sociedade neoliberal. Porto Alegre: Artmed Editora, 2001.

GUIMARÃES, Lêda B. Entre a Universidade e a Diversidade - A linha vermeIha do Ensino da Arte. Tese de Doutorado. ECA-USP, 2005.

GUIMARÃES, L; GUIMARÃES, A e GOYA, F. Objetos Populares da Cidade de Goiás-cerâmica. UFG-SEBRAE, Goiânia:2001.

HERNANDEZ, Fernando. Cultura Visual, mudança educativa e projeto de trabalho. Trad. Jussara Haubert Rodrigues. Porto Alegre: Artes Médicas Sul, 2000. 
Variações em torno dos jogos estéticos, artísticos e pedagógicos no ensino "superior" de artes visuais

HOISEL, E. Os Discursos Sobre a Literatura. In: COUTINHO, Eduardo F. (Org.). Fronteiras Imaginadas: cultura nacional/teoria internacional. Rio de Janeiro: Aeroplano, 2002.

McLAREN, Peter. Multiculturalismo Crítico. Tradu Bebel Orofino Schaefer. $3^{a}$ ed.-São Paulo: Cortez: Instituto Paulo Freire, 2000. - ( Coleção Prospectiva, v.3

MELLO e SOUZA, L. Introdução. In: RAMINELLI, R. Imagens da colonização: a representação do índio de Caminha e Vieira. Rio de Jsneiro: Jorge Zahar, 1996.

MORIN, E. Os sete saberes necessários à educação do futuro. São Paulo: Cortez, Brasília: Unesco, 2000.

RICHTER, Ivone Mendes. Multiculturalidade e Estética do Cotidiano no Ensino das Artes Visuais. Campinas, SP : Mercado das Letras, 2003.

SANTOMÉ, J. T. Globalização e interdisciplinaridade: o currículo integrado. Porto Alegre: Editora Artes Médicas Sul Ltda., 1998.

SANTOS, B. de S. Pela mão de Alice: o social e o político na pós-modernidade. São Paulo: Cortez, 1999.

\section{Leda Guimarães}

Doutora em Artes pela Escola de Comunicação e Artes-ECA da USP, mestre em Educação e Linguagens pela UFPI. Professora da Faculdade de Artes Visuais da UFG. Atua na Licenciatura, na Especialização em Arte Contemporânea e no Mestrado em Cultura Visual. 